\title{
Evaluasi Penjadwalan Waktu Pada Proyek Pembangunan Rumah Tipe 30 Di Istana Tegal Besar Kabupaten Jember Dengan Metode CPM
}

\author{
(Evaluation Of Time Schedule Of Type 30 Housing Development Projects In Istana Tegal \\ Besar Of Jember With CPM Method)
}

\author{
Firdaus Hidayatul Iman, Hadi Wahyono, Eka Bambang Gusminto* \\ Manajemen, Fakultas Ekonomi dan Bisnis, Universitas Jember (UNEJ) \\ Jln. Kalimantan 37, Jember 68121 \\ E-mail: firdaushidayatuliman@yahoo.co.id
}

\begin{abstract}
Abstrak
Penelitian ini dilakukan untuk mengevaluasi penjadwalan waktu pada proyek pembangunan rumah tipe 30 di Istana Tegal Besar Jember. Penelitian ini merupakan penelitian action research dengan menggunakan metode CPM. Data yang digunakan dalam penelitian adalah data primer dan data sekunder. Data primer dalam penelitian ini adalah data tentang berapa lama pembangunan rumah tipe 30 dan biaya yang dikeluarkan untuk membangun rumah tipe 30 di Istana Tegal Besar Jember. Berdasarkan hasil penelitian diketahui bahwa pembangunan rumah tipe 30 di Istana Tegal Besar Jember berdasarkan metode CPM selama 54 hari. Sedangkan biaya yang keluar untuk membangun rumah tipe 30 berdasarkan jalur kritis metode CPM sebesar Rp 43.983403. Dari segi biaya,penyelesaian proyek tersebut tidak ada perbedaan karena PT. Kinansyah Adi Jaya Land menggunakan sistem borongan dan rumah tipe 30 sudah bersubsidi dari pemerintah.
\end{abstract}

Kata kunci: Waktu, Jalur Kritis, Critical Path Method (CPM)

\begin{abstract}
This research was conducted to evaluate the scheduling of time in the project of building type 30 house in Tegal Besar Jember Palace. This research is an action research research using CPM method. The data used in this research are primary data and secondary data. Primary data in this research is data about how long building type 30 housing and expenses incurred to build type 30 house in Tegal Besar Palace Jember. Based on the result of research known that building of type 30 house in Tegal Besar Jember Palace based on CPM method for 54 days. While the cost out to build a type 30 house based on the critical path CPM method of Rp 43.983403. In terms of cost, the completion of the projects is no different because PT. Kinansyah Adi Jaya Land uses wholesale system and housing type 30 subsidized by government
\end{abstract}

Keywords: Time, Critical Path, Critical Path Method (CPM)

\section{Pendahuluan}

Proyek dapat diartikan sebagai kegiatan yang berlangsung dalam jangka waktu yang terbatas dengan mengalokasikan sumberdaya tertentu dan dimaksudkan untuk menghasilkan produk atau deliverable yang kriteria mutunya telah digariskan dengan jelas (Soeharto, 1999). Semakin bertambahnya kualitas teknologi, populasi dan kebutuhan akan bangunan yang berkualitas dan berteknologi tinggi yang melibatkan bahan-bahan (material), tenaga kerja dan teknologi yang semakin canggih. Proyek pada umumnya memiliki batasan waktu (deadline), artinya proyek harus selesai pada saat atau sebelum waktu yang telah ditentukan.

Keberhasilan atau kegagalan dari sebuah proyek sering disebabkan kurang terencananya kegiatan proyek serta pengendalian yang kurang efektif, sehingga kegiatan proyek tidak efisien, hal ini mengakibatkan keterlambatan, menurunnya kualitas pekerjaan dan membengkaknya biaya pelaksanaan. Keterlambatan penyelesaian proyek sendiri adalah kondisi yang sangat tidak dikehendaki, karena hal ini dapat merugikan kedua belah pihak baik dari segi waktu maupun biaya. Tuntutan pembangunan disegala bidang semakin dirasakan, terutama di negara yang sedang berkembang, hal ini dilakukan dalam rangka meningkatkan taraf hidup rakyatnya. Pembangunan tersebut berupa pembangunan fisik proyek, pembangunan gedung, jembatan, jalan tol, perumahan, dan lain-lain.

Kebutuhan akan tempat tinggal merupakan kebutuhan pokok bagi setiap orang. Sebagaimana kita ketahui oleh setiap orang untuk dapat melangsungkan hidup. Dewasa ini banyak bermunculan perusahaan industri perumahan atau pengembang perumahan. Hal tersebut dipengaruhi oleh permintaan rumah yang selalu meningkat dari tahun ke tahun. Sasaran penjualan perumahan adalah semua lapisan masyarakat. Karena peluang tersebut, maka pengembang perumahan bersaing untuk memenuhi permintaan masyarakat yaitu dengan membangun perumahan sesuai kebutuhan dan selera mereka. Ketatnya persaingan dalam bisnis perumahan ini, menuntut para pengelola perusahaan untuk dapat lebih berhati-hati dalam menjalankan usahanya. Perlu adanya perencanaan yang baik dalam menjalankan proyek tersebut. Mulai dari memilih lokasi perumahan, desain rumah, sasaran yang dituju, sampai mengenai pelaksanaan proyek.

Rumah atau perumahan sebagai kebutuhan primer setiap manusia harus segera terpenuhi. Dalam hal ini PT Kinansyah Adi Jaya Land sebagai salah satu perusahaan kontraktor yang berada di Kabupaten Jember menyediakan dan mengembangkan suatu proyek untuk membangun perumahan yang ada di Kabupaten Jember mulai tahun 2013. PT Kinansyah Adi Jaya Land berkantor di Jalan Kaliurang No 7

* Corresponding author 
Jember. Proyek perumahan yang telah dikembangkan oleh perusahaan kotraktor ini yaitu Perumahan Istana Tegal Besar, Perumahan Kaliurang Green Garden, dan Perumahan New Tegal Besar Cluster.

Istana Tegal Besar adalah salah satu proyek pembangunan perumahan yang dibangun oleh PT. Kinansyah Adi Jaya Land yang bertempat di Jalan Moh. Yamin Kaliwates Kabupaten Jember. Sebagian besar pembeli di perumahan ini memilih rumah tipe 30 dan rumah tipe 30 menjadi rumah paling banyak dibeli. Pembangunan perumahan ditentukan oleh pelunasan pembayaran dari pembeli, kapanpun pembeli melunasi pembayaran rumah maka saat itu juga kontraktor memulai membangun rumah yang telah dilunasi pembeli tersebut. Dalam waktu atau musim apapun rumah akan dibangun meskipun dalam musim hujan. Pembangunan pada musim hujan tepatnya pada bulan November 2016 terdapat kendala yaitu sisa-sisa semen disekitar genting yang menutupi saliran pembuangan air hujan dari genting, sehingga air hujan mengalir ke atap rumah sebelah yang sudah jadi dan merusak asbes atau langit-langit rumah tersebut hingga runtuh. Oleh karena itu, penulis ingin meneliti tentang proyek pembangunan rumah tipe $30 \mathrm{di}$ Istana Tegal Besar Jember. Berikut adalah data jumlah rumah berdasarkan tipe rumah di Istana Tegal Besar Jember.

Dalam hal ini penjadwalan proyek yang akan dibahas tentang mencari lintasan kritis, sehingga dapat diketahui berapa durasi dan biaya yang diperlukan untuk membangun Rumah Tipe 30 Di Istana Tegal Besar Kabupaten Jember Dengan Metode CPM.

\section{Metode}

Berdasarkan latar belakang masalah dan rumusan masalah yang ada, penelitian ini menggunakan jenis penelitian action research atau penelitian tindakan. Action research merupakan salah satu bentuk rancangan penelitian, dalam penelitian ini peneliti mendeskripsikan, menginterpretasi dan menjelaskan suatu situasi dengan melakukan perubahan dengan tujuan perbaikan. Menurut Gunawan (2007), action research adalah kegiatan atau tindakan perbaikan sesuatu yang perencanaan, pelaksanaan dan evaluasinya digarap secara sistematik sehinga validitas dan reabilitasnya mencapai tingkat riset. Action research juga merupakan proses yang mencakup siklus aksi, yang mendasarkan pada refleksi; umpan balik (feedback); bukti (evidence) dan evaluasi atas aksi sebelumnya dan situasi sekarang.

Pemilihan jenis penelitian ini didasarkan pada judul penelitian yang mengarah pada pembuatan perencanaan jaringan kerja sehingga tepat bila menggunakan jenis penelitian action research. Disini akan dibuat suatu model perencanaan kegiatan proyek dengan menggunakan network planning yaitu CPM dalam merencanakan waktu dan biaya dalam kegiatan proyek.

Menurut Heizer dan Render (2006), CPM membuat asumsi bahwa waktu kegiatan diketahui pasti, sehingga hanya diperlukan satu faktor untuk tiap kegiatan. Pada CPM dipakai cara "deterministik", yaitu memakai satu angka estimasi.

Sistematika dari proses penyusunan jaringan kerja (network) adalah sebagai berikut (Soeharto, 1999) : a. Mengkaji dan mengidentifikasi lingkup proyek, menguraikan, memecahkannya menjadi kegiatan-kegiatan atau kelompok kegiatan yang merupakan komponen proyek.

b. Menyusun kembali komponen-komponen pada butir 1, menjadi mata rantai dengan urutan yang sesuai logika ketergantungan.

c. Memberikan perkiraan kurun waktu bagi masing-masing kegiatan yang dihasilkan dari penguraian lingkup proyek.

d. Mengidentifikasi jalur kritis (critical path) dan fload pada jaringan kerja.

Setelah jalur kritis diketahui, langkah-langkahnya adalah sebagai berikut :

a. Menentukan waktu percepatan dan menghitung biaya tambahan untuk percepatan setiap kegiatan.

b. Mempercepat kritis waktu penyelesaian proyek dengan mengutamakan kegiatan kritis yang memiliki slope biaya terendah. Apabila upaya percepatan dilakukan pada aktivitias-aktivitas yang tidak berada pada jalur kritis, maka waktu penyelesaian keseluruhannya tidak berkurang.

c. Menyusun kembali jaringan kerjanya.

d. Mengulangi langkah kedua dan berhenti melakukan upaya percepatan apabila terjadi pertambahan jalur kritis. Apabila terdapat lebih dari satu jalur kritis, maka upaya percepatan dilakukan serentak pada semua aktivitas yang berada pada lintasan kritis. Usahakan agar tidak terjadi penambahan atau pemindahan jalur kritis apabila diadakan percepatan durasi pada salah satu kegiatan.

e. Upaya percepatan dihentikan apabila aktivitas-aktivitas pada lintasan kritis telah jenuh seluruhnya (tidak mungkin ditekan lagi).

f. Menghitung biaya keseluruhan akibat percepatan untuk mengetahui total biaya proyek yang dikeluarkan.

\section{Mencari Jalur Kritis}

Menurut Heizer dan Render (2015), jalur kritis dapat dicari dengan terlebih dahulu menghitung earliest start (ES), latest start (LS), earliest finish (EF) dan latest finish (LF).

Untuk menghitung ES dan EF seluruh pekerjaan, dimulai dari awal sampek akhir proyek (forward pass). Formula untuk mencari EF adalah sebagai berikut:

$$
\mathrm{EF}=\mathrm{ES}+\mathrm{t}
$$

Untuk menghitung LS dan LF, dimulai dari akhir proyek menuju awal proyek (backward pass). Formula untuk menghitung LS adalah sebagai berikut:

$$
\mathrm{LS}=\mathrm{LF}-\mathrm{t}
$$

Untuk selanjutnya adalah mengidentifikasi setiap aktivitas yang termasuk dalam jalur kritis. Operasinya dengan menghitung slack time (waktu menganggur), formula yang digunakan adalah sebagai berikut:

$$
\text { Salck }=\mathrm{LS}-\mathrm{ES}=\mathrm{LF}-\mathrm{EF}
$$




\section{Hasil dan Pembahasan}

\section{Analisis Hubungan Keterkaitan Antar Kegiatan Proyek}

Network merupakan suatu model yang menggambarkan hubungan antara komponen-komponen kegiatan serta menjelaskan arus proyek dari awal kegiatan proyek hingga proyek terselesaikan. Penentuan urutan kegiatan proyek umumnya disusun berdasarkan tata cara kerjanya. Berikut adalah keterkaitan antara kegiatan dalam pembangunan rumah Tipe 30Di Istana Tegal Besar Kabupaten Jember.

Tabel 1. Hubungan Keterkaitan Antar Kegiatan Proyek

Daftar kegiatan proyek dengan durasi normal beserta kegiatan pendahulunya.

\begin{tabular}{lcc}
\hline Jenis Kegiatan & $\begin{array}{c}\text { Kode } \\
\text { Kegiatan }\end{array}$ & $\begin{array}{c}\text { Kegiatan } \\
\text { Pendahulu }\end{array}$ \\
\hline Pekerjaan persiapan & $\mathrm{A}$ & - \\
\hline Pekerjaan tanah danurugan & $\mathrm{B}$ & $\mathrm{A}$ \\
\hline $\begin{array}{l}\text { Pekerjaan pasangan: } \\
\text { - Batu pondasi } \\
\text { - Batu merah }\end{array}$ & $\mathrm{C} 1$ & $\mathrm{B}$ \\
\hline Pekerjaan Beton Bertulang & & $\mathrm{C} 1$ \\
\hline $\begin{array}{l}\text { Pekerjaan } \\
\text { plesteran/benangan } \\
\text { (tembok) }\end{array}$ & $\mathrm{E}$ & $\mathrm{C} 1$ \\
\hline $\begin{array}{l}\text { Pekerjaan Rangka Atap } \\
\text { Pekerjaan Penutup Atap }\end{array}$ & $\mathrm{F}$ & $\mathrm{G}$ \\
\hline $\begin{array}{l}\text { Pekerjaan langit-langit } \\
\text { Pekerjaan kusen pintu dan }\end{array}$ & $\mathrm{H}$ & $\mathrm{F}$ \\
$\begin{array}{l}\text { jendela: } \\
\text { - Pembuatan }\end{array}$ & $\mathrm{G}$ \\
- Pemasangan & $\mathrm{I}$ & $\mathrm{E}$ \\
\hline $\begin{array}{l}\text { Pekerjaan Penggantung } \\
\text { dan Pengunci }\end{array}$ & $\mathrm{J}$ & $\mathrm{G}, \mathrm{I} 1$ \\
\hline $\begin{array}{l}\text { Pekerjaan Lantai } \\
\text { Pekerjaan Sanitasi }\end{array}$ & $\mathrm{K}$ & $\mathrm{L}$ \\
\hline Pekerjaan Cat-Catan & $\mathrm{M}$ & $\mathrm{H}, \mathrm{J}$ \\
\hline
\end{tabular}

Membuat Diagram Network. Setelah diketahui keterkaitan antar kegiatan dalam proyek pembangunan rumah tipe 30 Istana Tegal besar Jember maka didapat diagram Network seperti berikut ini.

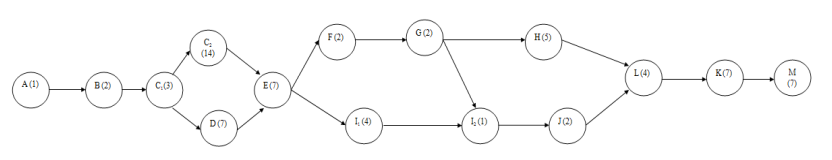

\section{Menghitung Forward Pass}

Tabel 4.4 Daftar Perhitungan Maju

\begin{tabular}{cccc}
\hline \multirow{2}{*}{$\begin{array}{c}\text { Kode } \\
\text { Kegiatan }\end{array}$} & Durasi (hari) & \multicolumn{2}{c}{ Paling Awal } \\
\cline { 2 - 4 } & & Mulai & Selesai \\
\hline A & 1 & 0 & 1 \\
\hline B & 2 & 1 & 3 \\
\hline C1 & 3 & 3 & 6 \\
\hline C $~$ & 14 & 6 & 20 \\
\hline D & 7 & 6 & 13 \\
\hline E & 7 & 20 & 27 \\
\hline F & 2 & 27 & 29 \\
\hline G & 2 & 29 & 31 \\
\hline H & 5 & 31 & 36 \\
\hline I1 & 4 & 27 & 31 \\
\hline I2 & 1 & 31 & 32 \\
\hline J & 2 & 32 & 34 \\
\hline K & 7 & 40 & 47 \\
\hline L & 4 & 36 & 40 \\
\hline M & 7 & 47 & 54 \\
\hline
\end{tabular}

Perhitungan Forward Pass menghasilkan angka 54 pada akhir kegiatan $M$ yang berarti bahwa kegiatan $M$ yang merupakan akhir dari semua proses penyelesaian proyek dan proyek pembangunan rumah tipe 30 di Istana Tegal Besar Kabupaten Jember diselesaikan selama 54 hari menurut perhitungan Forward Pass.

\section{Menghitung Bacward Pass}

Tabel 4.5 Daftar Perhitungan Mundur

\begin{tabular}{cccc}
\hline \multirow{2}{*}{$\begin{array}{l}\text { Kode } \\
\text { Kegiatan }\end{array}$} & Durasi (hari) & \multicolumn{2}{c}{ Paling Awal } \\
\cline { 2 - 4 } & & Mulai & Selesai \\
\hline A & 1 & 0 & 1 \\
\hline B & 2 & 1 & 3 \\
\hline C1 & 3 & 3 & 6 \\
\hline C2 & 14 & 6 & 20 \\
\hline D & 7 & 14 & 20 \\
\hline E & 7 & 20 & 27 \\
\hline F & 2 & 27 & 29 \\
\hline G & 2 & 29 & 31 \\
\hline H & 5 & 31 & 36 \\
\hline I1 & 4 & 29 & 33 \\
\hline I2 & 1 & 33 & 34 \\
\hline J & 2 & 34 & 36 \\
\hline K & 7 & 40 & 47 \\
\hline L & 4 & 36 & 40 \\
\hline M & 7 & 47 & 54 \\
\hline
\end{tabular}


Berdasarkan perhitungan mundur, dimana waktu selesai kegiatan $M$ yang merupakan kegiatan terakhir proyek dan menjadi waktu penyelesaian akhir suatu aktivitas menunjukkan waktu palng panjang atau paling lama, maka dapat disimpulkan bahwa perhitungan durasi proyek menggunakan metode CPM sebesar 54 hari.

\section{Menghitung Waktu Longgar}

Tabel 4.6 Daftar Hasil Perhitungan Waktu Longgar

\begin{tabular}{ccc}
\hline Kode Kegiatan & Durasi (hari) & Waktu Longgar \\
\hline$(1)$ & $(2)$ & $(3)$ \\
\hline A & 1 & 0 \\
\hline B & 2 & 0 \\
\hline C1 & 3 & 0 \\
\hline C2 & 14 & 0 \\
\hline D & 7 & 7 \\
\hline E & 7 & 0 \\
\hline F & 2 & 0 \\
\hline G & 2 & 0 \\
\hline H & 5 & 0 \\
\hline I & 4 & 2 \\
\hline I & 1 & 2 \\
\hline J & 2 & 2 \\
\hline K & 7 & 0 \\
\hline L & 4 & 0 \\
\hline M & 7 & 0 \\
\hline
\end{tabular}

\section{Pembahasan}

Dengan menggunakan metode CPM melalui perhitungan maju, perhitungan mundur dan perhitungan waktu longgar (float time) dapat diketahui bentuk jaringan kerja pada proyek pembangunan rumah tipe 30 di Istana Tegal Besar Jember dan kegiatan apa saja yang masuk dalam jalur kritis. Kegiatan yang masuk dalam jalur kritis adalah $\mathrm{A}-\mathrm{B}-\mathrm{C}_{1}-\mathrm{C}_{2}$-E-F-G-H-

L-K-M, dengan rincian kegiatan: pekerjaan persiapan, pekerjaan tanah dan urugan, pekerjaan pasangan batu pondasi, pekerjaan pasangan batu merah, pekerjaan plesteran/benangan (tembok), pekerjaan rangka atap, pekerjaan penutup atap, pekerjaan langit-langit, pekerjaan sanitasi, pekerjaan lantai, pekerjaan cat-catan.

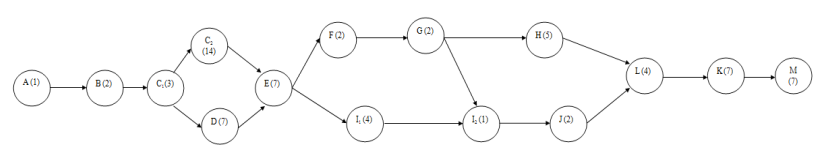

Berdasarkan data yang diperoleh dari PT. Kinansyah Adi Jaya Land diperoleh data bahwa penyelesaian proyek tersebut dapat terselesaikan dalam 68 hari. Dalam pelaksanaan proyek tersebut membutuhkan dana sebesar Rp 43.983.403.

Dengan menggunakan metode CPM, didapatkan hasil bahwa pengerjaan proyek dapat terselesaikan dalam jangka waktu 54 hari dengan total biaya sebesar Rp 43.983.403. Sedangkan pengerjaan proyek menurut perhitungan perusahaan atau kontraktor menggunakan Ms. Project selama 68 hari kerja.

Waktu dan biaya yang dibutuhkan oleh PT. Kinansyah Adi Jaya Land dengan kurun waktu penyelesaian proyek selama 68 hari yaitu sebesar Rp 43.983.403, sedangkan waktu dan biaya proyek yang dibutuhkan apabila menggunakan metode network planning dengan kurun waktu penyelesaian proyek selama 54 hari sebesar Rp 43.983.403 . Dari segi biaya, penyelesaian proyek tersebut tidak ada perbedaan karena PT. Kinansyah Adi Jaya Land menggunakan sistem borongan dan rumah tipe 30 sudah bersubsidi dari pemerintah.

\section{Simpulan}

Berdasarkan penelitian yang telah dilakukan terhadap proyek pembangunan rumah tipe 30 di Istana Tegal Besar Jember maka didapat kesimpulan sebagai berikut:

Waktu dan biaya yang diperlukan untuk menyelesaikan proyek pada jadwal yang sudah ditentukan oleh kontraktor pada proyek pembangunan rumah tipe 30 di Istana Tegal Besar Jember berdasarkan data yang telah diberikan oleh kontraktor dalam hal ini PT. Kinansyah Adi Jaya Land yaitu 68 hari dengan menghabiskan dana sebesar Rp 43.983.403.

Dengan menggunakan metode network planning dapat diketahui bentuk jaringan kerja dan kegiatan apa saja yang termasuk dalam jalur kritis. Kegiatan yang berada dalam jalur kritis adalah $\mathrm{A}-\mathrm{B}-\mathrm{C}_{1}-\mathrm{C}_{2}-\mathrm{E}-\mathrm{F}-\mathrm{G}-\mathrm{H}-\mathrm{L}-\mathrm{K}-\mathrm{M}$, dengan rincian kegiatan yaitu : pekerjaan persiapan, pekerjaan tanah dan urugan, pekerjaan pasangan batu pondasi, pekerjaan pasangan batu merah, pekerjaan plesteran/benangan (tembok), pekerjaan rangka atap, pekerjaan penutup atap, pekerjaan langit-langit, pekerjaan sanitasi, pekerjaan lantai, pekerjaan cat-catan. Penjadwalan proyek pembangunan rumah tipe 30 di Istana Tegal Besar Kabepaten Jember menggunakan metode CPM dapat terselesaikan selama 54 hari dengan total biaya yang dibutuhkan sebesar $\mathrm{Rp}$ 43.983.403.

Dari hasil analisis yang telah dilakukan, waktu dan biaya yang dibutuhkan untuk mengerjakan proyek pembangunan rumah tipe 30 di Istana Tegal Besar Jember lebih efisien menggunakan metode network planning. Waktu penyelesaian proyek adalah 68 hari dan perkiraan waktu menggunakan network planning adalah 54 hari, terjadi selisih selama 20 hari. Biaya yang telah dikeluarkan sebesar $\mathrm{Rp} 43.983 .403$ sedangkan perkiraan biaya dengan menggunakan metode network planning sebesar Rp 43.983.403 , Dari segi biaya, penyelesaian proyek tersebut tidak ada perbedaan karena PT. Kinansyah Adi Jaya Land menggunakan sistem borongan dan rumah tipe 30 sudah bersubsidi dari pemerintah.

\section{Saran}

Berdasarkan hasil penelitian yang telah dilakukan pada proyek pembangunan rumah tipe 30 di Istana Tegal Besar Jember, dapat dijadikan referensi atau perbandingan mengenai efektivitas dan efisiensi proyek oleh pihak kontraktor dalam hal ini PT. Kinansyah Adi Jaya Land. Keterkaitan antar kegiatan satu dengan yang lain juga harus dipertimbangkan dan diperhitungkan dengan baik supaya tidak ada kendala-kendala non teknis seperti keterlambatan bahan bangunan serta untuk memaksimalkan waktu dan biaya proyek.

Perkerjaan yang ada di jalur kritis harus mendapatkan pengawasan lebih agar tidak tertunda karena hal-hal non teknis karena penundaan kegiatan jalur kritis mengakibatkan tertundanya penyelesaian proyek secara keseluruhan. Selisih waktu diatas dapat dimanfaatkan perusahaan untuk 
memperbaiki atau pengecekkan kembali dan bahkan bisa memulai untuk mengerjakan proyek selanjutnya.

Sebaiknya perusahaan menggunakan network planning dengan metode CPM. Dimana metode tersebut dapat membantu perusahaan untuk melakukan efisiensi waktu pelaksanaan dan biaya proyek dalam membuat suatu perencanaan dan penjadwalan. Sehingga kegiatan yang dilakukan dapat terlaksana lebih efektif dalam menyelesaikan suatu proyek.

\section{Referensi}

Gunawan. 2007. Genius Learning Strategy. Jakarta: Gramedia Pustaka Utama..

Harry Hartawan, n.d. "Analisa Keterlibatan Manajemen Proyek Dalam Proses Perencanaan dan Pengendalian Proyek Selama Pelaksanaan Konstruksi". Jurnal Thesis.

Heizer, Jay dan Rander, Barry. 2006. Manajemen Operasi. Edisi Sembilan. Jakarta: Salemba Empat.

Heizer, Jay dan Rander, Barry. 2015. Manajemen Operasi. Edisi Sebelas. Jakarta: Salemba Empat.

Soeharto. 1999. Manajemen Proyek Dari Konseptual Sampai Operasional. Jilid I. Edisi kedua. Jakarta: Erlangga. 